\title{
Near real-time estimation of water vapour in the troposphere using ground GNSS and the meteorological data
}

\author{
J. Bosy, J. Kaplon, W. Rohm, J. Sierny, and T. Hadas \\ Institute of Geodesy and Geoinformatics, Wroclaw University of Environmental and Life Sciences, Grunwaldzka 53, \\ 50-357 Wroclaw, Poland
}

Correspondence to: J. Bosy (jaroslaw.bosy@up.wroc.pl)

Received: 4 April 2012 - Revised: 23 August 2012 - Accepted: 3 September 2012 - Published: 27 September 2012

\begin{abstract}
The near real-time (NRT) high resolution water vapour distribution models can be constructed based on GNSS observations delivered from Ground Base Augmentation Systems (GBAS) and ground meteorological data. Since 2008 in the territory of Poland, a GBAS system called ASGEUPOS (Active Geodetic Network) has been operating. This paper addresses the problems concerning construction of the NRT model of water vapour distribution in the troposphere near Poland. The first section presents all available GNSS and ground meteorological stations in the area of Poland and neighbouring countries. In this section, data feeding scheme is discussed, together with timeline and time resolution. The high consistency between measured and interpolated temperature value is shown, whereas some discrepancy in the pressure is observed. In the second section, the NRT GNSS data processing strategy of ASG-EUPOS network is discussed. Preliminary results show fine alignment of the obtained Zenith Troposphere Delays (ZTDs) with reference data from European Permanent Network (EPN) processing center. The validation of NRT troposphere products against daily solution shows $15 \mathrm{~mm}$ standard deviation of obtained ZTD differences. The last section presents the first results of 2-D water vapour distribution above the GNSS network and application of the tomographic model to 3-D distribution of water vapour in the atmosphere. The GNSS tomography model, working on the simulated data from numerical forecast model, shows high consistency with the reference data (by means of standard deviation $4 \mathrm{~mm} \mathrm{~km}^{-1}$ or $4 \mathrm{ppm}$ ), however, noise analysis shows high solution sensitivity to errors in observations. The discrepancy for real data preliminary solution (measured as a mean standard deviation) between reference NWP data and tomography data was on the level of $9 \mathrm{~mm} \mathrm{~km}^{-1}$ (or $9 \mathrm{ppm}$ ) in terms of wet refractivity.
\end{abstract}

Keywords. Meteorology and atmospheric dynamics (Mesoscale meteorology; Synoptic-scale meteorology) Radio science (Remote sensing)

\section{Introduction}

Global Navigation Satellite System (GNSS) was originally designed for positioning and navigation. Amongst other possible applications it can also be used to derive information about the state of the atmosphere, what is now recognised as GNSS meteorology. Particularly GNSS meteorology is the remote-sensing of the atmosphere from a satellite platform (GNSS radio occultation meteorology) (Anthes et al., 2008; Wickert et al., 2009) and ground permanent stations (ground based GNSS meteorology) (Bevis et al., 1992, 1994; Bender et al., 2011).

Continuous observations from GNSS receivers provide an excellent tool for monitoring water vapour content in the Earth's atmosphere. Several research projects were initiated in Europe and overseas to derive the water vapour content in the atmosphere from ground-based GNSS observation data, for example: COST Action 716 (European Cooperation in the field of Scientific Technical Research-exploitation of ground-based GPS for climate and numerical weather prediction applications, 1998-2004) (van der Marel, 2004; Dousa, 2004), TOUGH (Targeting Optimal Use of GPS Humidity Data in Meteorology, 2003-2006) (Vedel and Huang, 2004; Järvinen et al., 2007) and E-GVAP (The EUMETNET GPS Water Vapour Programme, 2004-) (Dousa, 2010a; Bennitt and Jupp, 2012). The near real-time (NRT) GNSS water vapour monitoring for numerical weather prediction services 
are active in Germany (Heise et al., 2009) and Austria (Karabatic et al., 2011).

The GNSS meteorology is based on the results of GNSS data processing represented by the Zenith Total Delay (ZTD). The ZTD can be split into hydrostatic ZHD and wet ZWD component of the delay:

$\mathrm{ZTD}=\mathrm{ZHD}+\mathrm{ZWD}$

The hydrostatic component ZHD is modelled based on the pressure or pressure and temperature at the GNSS stations which might be obtained from deterministic atmosphere models, as well as Numerical Weather Prediction (NWP) models or from ground meteorological observations.

The wet component of Zenith Tropospheric Delay (ZWD) is the foundation for the computing of water vapour content in the atmosphere. The integrated content of water vapour above GNSS stations (2-D model), represented by Integrated Water Vapour (IWV), is obtained directly from ZWD applying empirical equations (Bevis et al., 1992, 1994).

The spatial structure and temporal behaviour of the water vapour in the troposphere (3-D) can be modelled using the GNSS tomography method. In principle, GNSS tomography is founded on the linear equation relating Slant Wet Delay (SWD) with the wet refractivity in voxels $N_{\mathrm{w}}$ along the raypath which reads as follows (i.e., Flores et al., 2000):

$\mathrm{SWD}=\mathbf{A} \cdot N_{\mathrm{W}}$

where $\mathbf{A}$ is the design matrix.

Wet refractivity $N_{\mathrm{w}}$ is a dimensionless quantity and by definition of refraction contains $10^{-6}$ term, therefore, may be presented either in ppm or in $\mathrm{mm} \mathrm{km}^{-1}$ (interchangeable). In this study, authors choose to present wet refractivity results in $\mathrm{mm} \mathrm{km}^{-1}$.

The design matrix construction is at the focal point of all tomography applications (Perler et al., 2011; Nilsson and Gradinarsky, 2006), because it relates to the SWD sum of all wet refractivities voxels along the path multiplied by the distance that the signal resides in each voxel, which is a linear operator. Currently several methods exist to solve Eq. (2). The first is to add horizontal and vertical constraints into the system of equations (2) and then solve it (Hirahara, 2000), the second is to use a Kalman filter with the same equation system (Flores et al., 2000), the third is to find the solution directly from the GNSS phase measurement equation (Nilsson and Gradinarsky, 2006) and another is Algebraic Reconstruction Technique (ART) (Bender et al., 2011). In previous papers by Rohm and Bosy $(2009,2011)$, the authors showed GNSS tomography methodology studies based on minimum constraint solution and Singular Value Decomposition (SVD) algorithm (Anderson et al., 1999) to find the wet refractivity (Eq. 2) above the network of GNSS receivers.

A number of GNSS applications require precise positioning with high accuracy in real-time or rapid static postprocessing mode. Precise positioning in real-time or rapid static

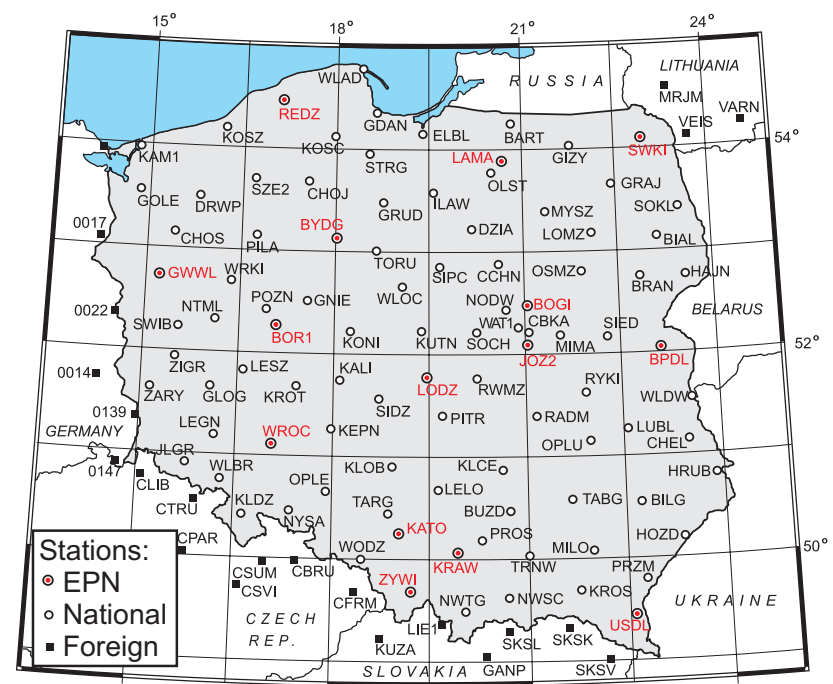

Fig. 1. Reference stations of ASG-EUPOS system (www.asgeupos.pl): 15 EPN, 85 national, 25 foreign (7 November 2011).

mode is currently being implemented in two methods: differential and autonomous. The positioning using the above methods can be supported by Ground Base Augmentation System (GBAS), which provides better results stability in the area of the GBAS network (Kee et al., 1991). One of the elements supporting precise positioning, especially for height component, is a model of the neutral atmosphere (troposphere), computed for the GBAS network area (Wielgosz et al., 2011; Grejner-Brzezinska et al., 2009). The Poland territory is covered by dense network of GNSS stations in the frame of a GBAS system called ASG-EUPOS.

The first part of the paper contains the procedure of integration and validation of ground-based meteorological observations delivered from various sources on the area of GBAS ASG-EUPOS network. The second part presents the methodology of NRT GNSS data processing of ASG-EUPOS stations for ZTD estimation with reference data and products from EPN/IGS processing centers. The third part presents the procedure of water vapour 2-D distribution above GNSS stations and tomographic model application to estimate 3-D distribution of water vapour in the atmosphere.

\section{GNSS and meteorological data}

The ASG-EUPOS system permanently collects the GNSS data from 125 stations (Fig. 1).

Complying with the EUPOS organisation (www.eupos. org) and the project of the ASG-EUPOS system standards, the distances between neighbouring reference stations should be $70 \mathrm{~km}$ which gives the number of stations 100 in the area of Poland. According to the rules of the EUPOS organisation (in the frame of cross-border data 


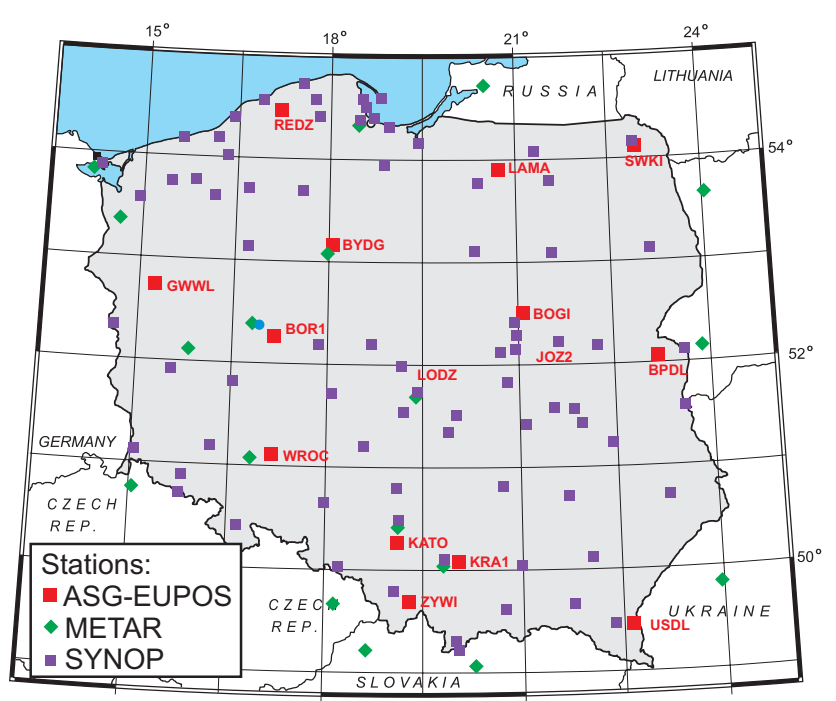

Fig. 2. Ground stations of meteorological networks (ASG-EUPOS: 15, METAR: 22, SYNOP: 84) in the area of Poland (7 November 2011).

exchange) the reference stations from Lithuania (LITPOS), Germany (SAPOS), Czech Republic (CZEPOS) and Slovakia (SKPOS) were added to the regular processing of the ASG-EUPOS network (Fig. 1) (Bosy et al., 2008).

In all localisations of the EUREF Permanent Network (EPN) stations (Fig. 1) in 2008, the new uniform meteorological infrastructure was installed. In all stations the basic meteorological parameters (pressure with precision $\pm 0.08 \mathrm{hPa}$ from 500 to $1100 \mathrm{hPa}$, temperature with precision $\pm 0.2^{\circ} \mathrm{C}$ from -50 to $+60^{\circ} \mathrm{C}$ and relative humidity with precision $\pm 2 \%$ from 0 to $100 \%$ ) are measured close to the GNSS antenna. This set of meteorological sensors are considered the most unified, homogenous (available with $1 \mathrm{~h}$ time resolution) and most consistent, therefore, in this study they are regarded as reference.

The ground meteorological observations in the area of Poland and neighbouring countries are also available from meteorological stations acting as a support for aviation: METAR (Meteorological Terminal Aviation Routine Weather Report or Meteorological Aerodrome Report) messages stations, or as a country meteorological data supply: SYNOP (surface synoptic observations) messages stations (Fig. 2).

The data are available with different time resolution (SYNOP: $3 \mathrm{~h}$, METAR: $0.5 \mathrm{~h}$ ). While the spatial distribution of METAR, SYNOP stations is complying with near realtime estimation of water vapour needs, the actual quality of the data remains unknown. This set of sensors is more dense than the previously mentioned and could be used to interpolate meteorological parameters for the rest of ASG-EUPOS GNSS stations not equipped with meteorological instrumentation.

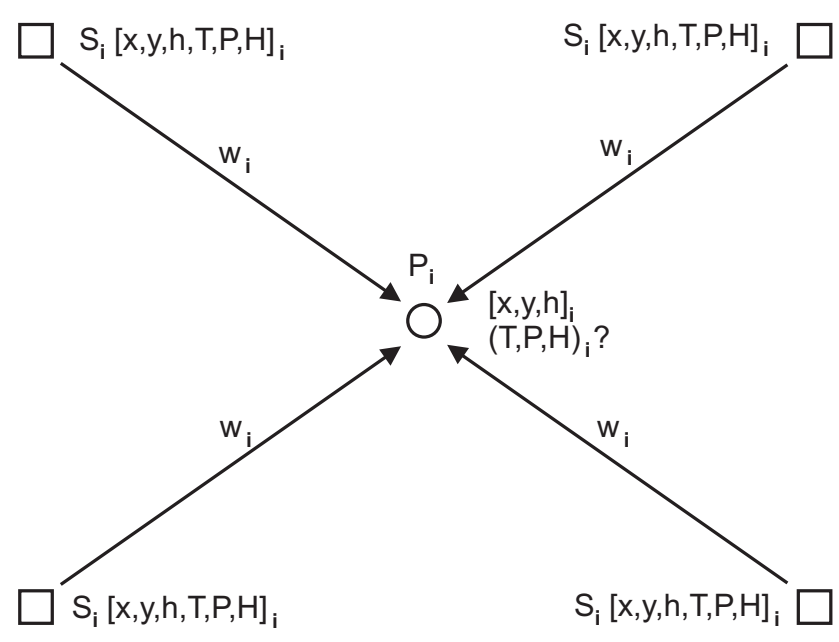

Fig. 3. Interpolation of the atmospheric parameters $(T-$ temperature, $H$ - relative humidity, $P$ - pressure) from the known meteorological stations $\left(S_{\mathrm{i}}\right)$ to a known location $\left(P_{\mathrm{i}}\right)$.

The values of temperature $T$, relative humidity $H$ and pressure $P$ are interpolated from the known $\left(S_{\mathrm{i}}\right)$ meteorological stations according to procedure, in which the idea is depicted in Fig. 3.

The value of the particular parameter is calculated as a weighted average:

$\bar{s}=\frac{\sum_{i=1}^{n} s_{\mathrm{i}} w_{\mathrm{i}}}{\sum_{i=1}^{n} w_{\mathrm{i}}}$,

where the values of weights $w_{\mathrm{i}}$ are calculated, using empirical formulas given by Borkowski et al. (2002), differently for temperature, relative humidity and pressure:

- Temperature: $s \longleftarrow T$

$w_{\mathrm{i}}=\left(h-h_{\mathrm{i}}\right)^{-4}$,

where $h$ and $h_{\mathrm{i}}$ are heights of the interpolated point and known points, respectively.

- Relative humidity: $s \longleftarrow H$

$w_{\mathrm{i}}=\left[\left(x-x_{\mathrm{i}}\right)^{2}+\left(y-y_{\mathrm{i}}\right)^{2}+\left(h-h_{\mathrm{i}}\right)^{2}\right]^{-2}$,

where $x, y$ are planar coordinates of the interpolated point and $x_{\mathrm{i}}, y_{\mathrm{i}}$ are coordinates of the known points used for the interpolation.

- Pressure: $s \longleftarrow P$

$w_{\mathrm{i}}=\left[\left(x-x_{\mathrm{i}}\right)^{2}+\left(y-y_{\mathrm{i}}\right)^{2}\right]^{-2}$

In this case, in the first step the values of pressure are calculated from known $\left(S_{\mathrm{i}}\right)$ points data (Fig. 3) using barometric levelling formula (Rankine and Bamber, 2009): 

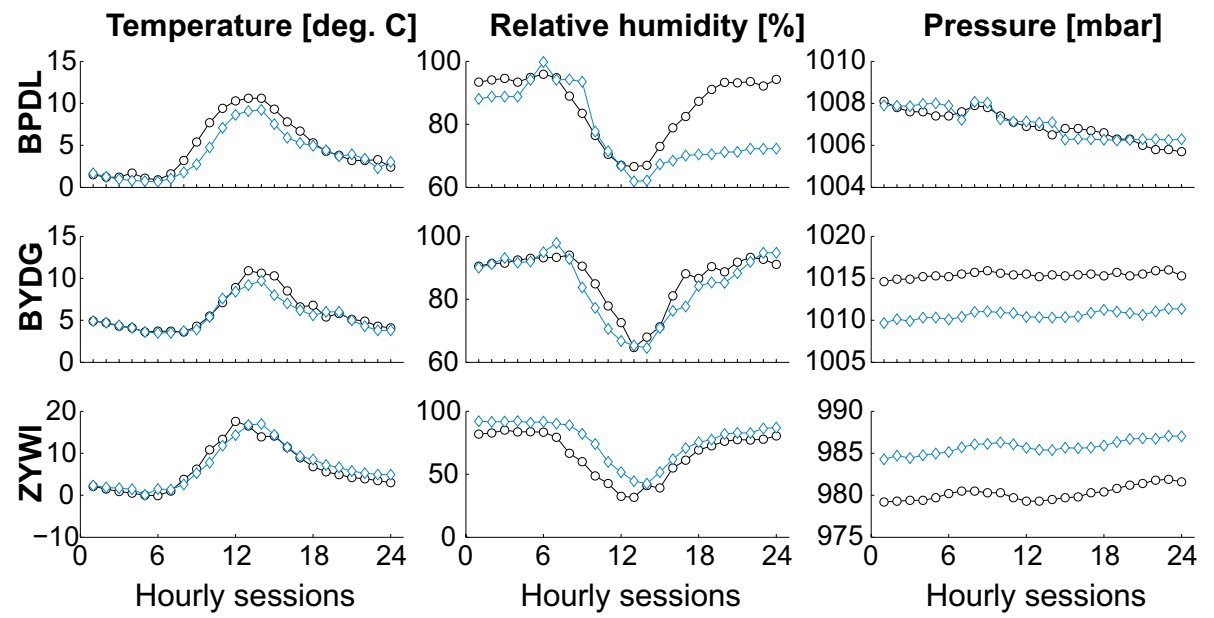

Fig. 4. Measured (black circles) and interpolated (blue diamonds) meteorological parameters for three stations: BPDL, BYDG, ZYWI on 7 November 2011.

$$
\log P_{\mathrm{i}}=\log P_{S_{\mathrm{i}}}+\frac{h_{\mathrm{i}}-h}{18400\left(1+\frac{T+T_{\mathrm{i}}}{546}\right)} .
$$

In the next step, the weighted average is determined from the calculated values.

In order to ascertain the quality of METAR and SYNOP observations, the values of meteorological parameters at the ASG-EUPOS meteorological sensors has been calculated using the procedure given above. Attained values were compared against observations, the residual statistics (average discrepancy and standard deviation) is shown in Table 1.

Temperature interpolation on most of the stations (in 8 out of 9) shows no large average discrepancies, but the other two parameters, mainly relative humidity and pressure, shows significant discrepancies. The lower accuracy for pressure and relative humidity is attributed to the spatial distribution of SYNOP, METAR stations (Fig. 2), which affects interpolation weights as follows in Eqs. (5), (6).

Figure 4 shows the results of a daily comparison (between measured and interpolated values) at the three selected meteorological stations: BPDL, BYDG and ZYWI.

As shown on Fig. 4, the temperature interpolation was successful, achieving high consistency with observations. Station BYDG is the example of the pressure point observations that shows systematic bias linked with low SYNOP, METAR stations density in BYDG station vicinity. Negative bias is observed in stations located in the mountainous part of Poland, with the example shown on Fig. 4 as ZYWI.

Maps (Fig. 5) show the 2-D distribution of temperature, relative humidity and air pressure interpolated from all available meteorological stations (METAR, SYNOP and GNSS) (Fig. 2).

Attained results (Table 1 and Fig. 4), shows unhomogenity of meteorological data, and some deficiencies in the interpo- lation procedure. Future work will focus on finding the optimal methods of interpolation and meteorological data validation.

\section{NRT ZTD estimation}

The NRT ZTD estimation service is organised to monitor the state of troposphere from GPS observations for the area of Poland. The only and best source of data for that purpose in Poland is the ASG-EUPOS network (Fig. 1). Service is based on capturing real-time streams of RTCM GPS data via the NTRIP protocol using the BNC 2.5 software (BKG, 2011). RINEX 2.11 files generated from RTCM streams are then supplemented with the latest station information data from the IGS and ASG-EUPOS station log files. Software for downloading the station information data, IGS products and Bernese GPS Software 5.0 Processing Engine (BPE) (Dach et al., 2007) scripts are written in Perl script language and initialised from cron Linux service. The schedule of collection of input data (GPS data and parameters) is presented in Table 2.

During the development of Bernese batch processing engine for ZTDs estimation, two methods of ambiguity resolution were established and tested: the standard QIF (Quasi Ionosphere-Free) method (Mervart, 1995) and L5/L3 method (Bosy et al., 2003; Dach et al., 2007). In the second method, the wide-lane L5 phase combination was used in the SIGMA ambiguity resolution strategy (Dach et al., 2007) and then resolved wide-lane ambiguities were introduced into a narrowlane L3 solution. Primarily for that purpose the GPS data was gathered from Polish EPN stations belonging to the ASG-EUPOS as well as from EPN solution fiducial stations BORI, JOZE, METS, ONSA, POLV, POTS, WTZR, ZIMM for referencing the solution according to the ITRF2005 combined EPN solution. Processing of GPS data were run in 
Table 1. Discrepancies of interpolated and real atmospheric parameters on selected ASG-EUPOS stations.

\begin{tabular}{|c|c|c|c|c|c|c|}
\hline \multirow[b]{2}{*}{ Station } & \multicolumn{3}{|c|}{ Average discrepancy } & \multicolumn{3}{|c|}{ Standard deviation } \\
\hline & Temp [deg. C] & Rel. hum. [\%] & Pressure [mbar] & Temp [deg. C] & Rel. hum. [\%] & Pressure [mbar] \\
\hline BPDL & 0.87 & 7.67 & -0.10 & 1.03 & 9.78 & 0.36 \\
\hline BYDG & 0.39 & 2.16 & 4.77 & 0.69 & 3.77 & 0.30 \\
\hline GWWL & 0.20 & -1.79 & 11.90 & 1.31 & 3.79 & 0.35 \\
\hline KATO & 3.91 & -13.35 & -11.98 & 2.50 & 6.24 & 0.22 \\
\hline REDZ & -0.39 & 4.61 & 6.17 & 0.69 & 4.81 & 0.46 \\
\hline SWKI & -1.61 & -0.85 & 10.08 & 1.24 & 5.88 & 0.40 \\
\hline USDL & -0.01 & -14.01 & -17.50 & 4.12 & 12.94 & 0.52 \\
\hline WROC & 1.82 & -10.48 & 2.12 & 1.09 & 4.53 & 0.33 \\
\hline ZYWI & -0.40 & -10.54 & -5.54 & 1.52 & 6.23 & 0.41 \\
\hline
\end{tabular}
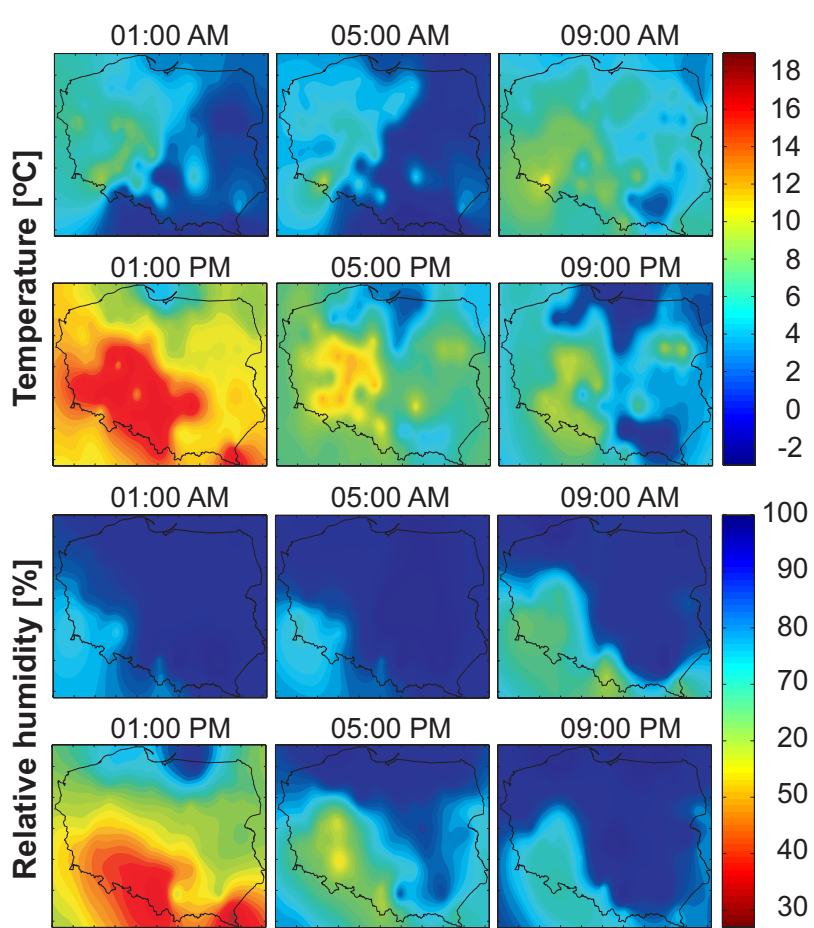

05:00 AM

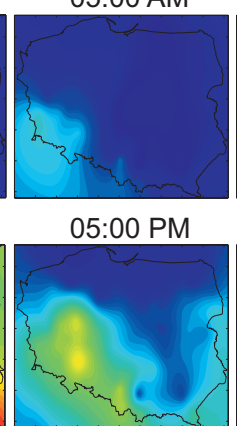

09:00 AM
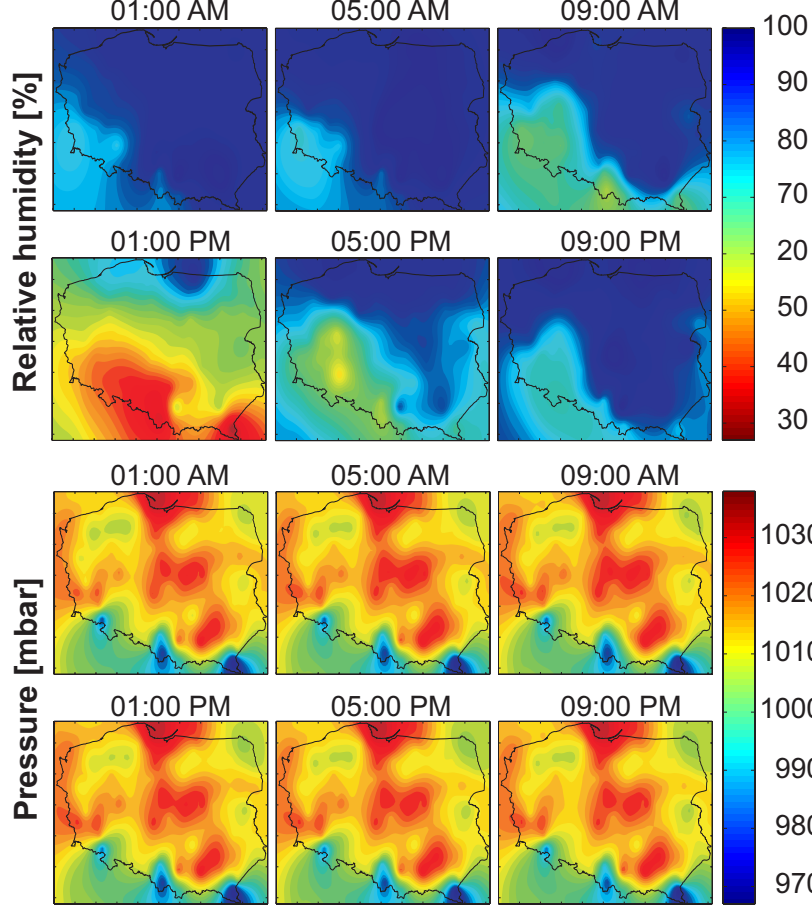

05:00 AM

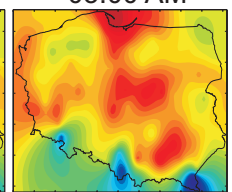

09:00 AM

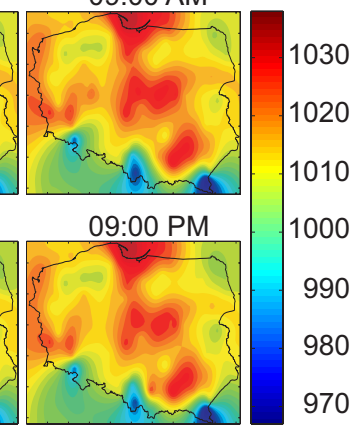

Fig. 5. Meteorological parameters interpolation for the area of Poland on 7 November 2011. Each map combines interpolated and measured data.
Table 2. Input data for the NRT processing of ZTD at Institute of Geodesy and Geoinformatics in Wroclaw.

\begin{tabular}{llc}
\hline Data & Source & Update \\
\hline & Input & \\
\hline GPS data & NTRIP RTCM & real-time \\
& stored to RINEX & \\
Precise Orbits & IGS Ultra-rapid & $6 \mathrm{~h}$ \\
ERP & IGS Ultra-rapid & $6 \mathrm{~h}$ \\
Satellite health info. & IGS & $1 \mathrm{~h}$ \\
\hline & Output & \\
\hline ZTD files & TRO SINEX & $1 \mathrm{~h}$ \\
Coordinate files & CRD and SINEX & $1 \mathrm{~h}$ \\
\hline
\end{tabular}

$12 \mathrm{~h}$ windows each hour. The results from both strategies were compared and L5/L3 strategy was recognised as better, because of greater average ambiguity resolution percentage (82.0\% L5/L3 against $80.0 \%$ QIF) and shorter average computation time for the processing window for $21 \mathrm{EPN}$ stations (3min 53s L5/L3 against 4 min $2 \mathrm{~s}$ QIF). The resultant ZTDs were compared to the EPN combined ZTD solution for 19 stations of 21 stations presented in Fig. 7 and the $9.3 \mathrm{~mm}$ standard deviation of obtained differences was achieved with average bias of $-0.2 \mathrm{~mm}$. The comparison of ZTDs for April and November of year 2011 is shown in Fig. 6. This figure depicts also the percentage of ZTD differences within double standard deviation boundaries and the range of obtained differences. It is visible, that for analysed stations 4 to $10 \%$ of data are outliers exceeding double standard deviation value.

GPS data processing was based on the solution of the set of independent baselines (Fig. 7) connecting 14 Polish and 6 foreign EPN stations. Other stations in the further processing were connected to this network of baselines using the SHORTEST strategy (Dach et al., 2007). Final minimum constrained solution was referenced to ITRF2005 by the epoch coordinates of EPN fiducial stations. The results of such a solution are then comparable to ASG-EUPOS and 

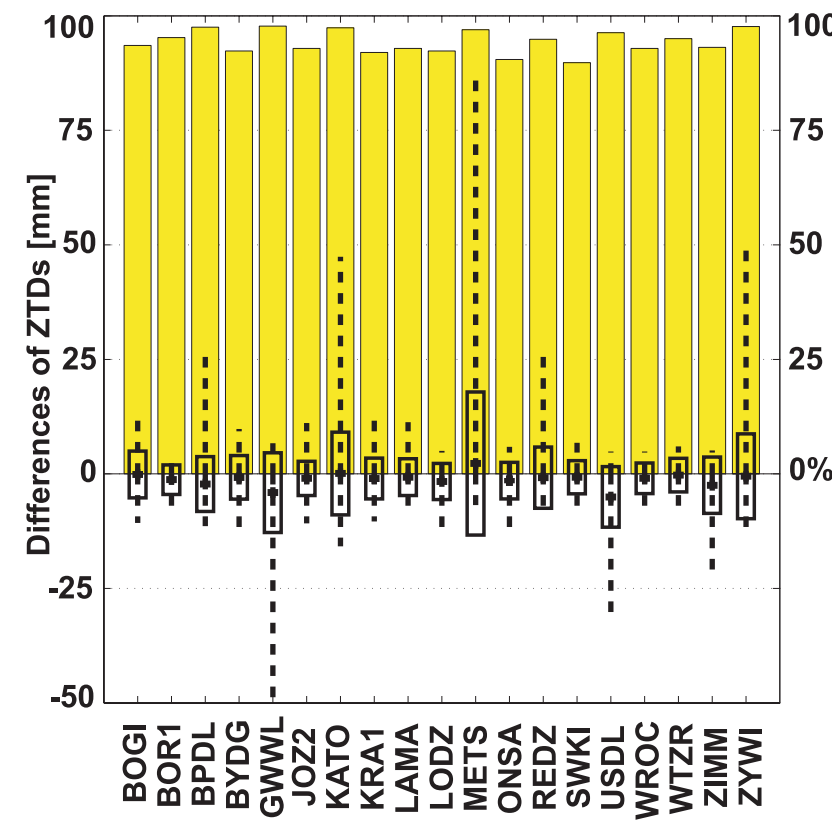

- Mean value $\square+/$ - Standard deviation
$\square$ Percentage of ZTD differences within $+/$ - 2 std. dev.

Fig. 6. Comparison of estimated NRT ZTDs with EPN combined ZTD solution for 19 EPN stations, during April and November of 2011.

EPN/IGS daily solutions and allows for the network consistency monitoring. Obtained differences of NRT ZTDs with EPN combined product (for April and November of 2011) shows the repeatability of ellipsoidal height component with standard deviation of $28.4 \mathrm{~mm}$ and average for all stations bias of $-13 \mathrm{~mm}$. This rather big value of bias was considered as the problem of the incorrect constraining of solutions and improved during the processing of entire network consisting of EPN and ASG-EUPOS stations.

Processing of whole the network consisting of 97 Polish ASG-EUPOS stations and 6 foreign EPN stations was also tested. The processing strategy description is presented in Table 3. The moving computation window was shortened first from 12 to $4 \mathrm{~h}$ due to the server limited processing performance and next to last one hour. Processing a priori ZTD model is Saastamoinen with Dry Niell mapping functions with the final estimation of Wet Niell model values which is a standard Bernese GPS Software processing procedure (Dach et al., 2007). Taking into account height bias $(-13 \mathrm{~mm})$ obtained during testing period, constraining of solutions was made on ITRF2008 coordinates of 23 EPN stations obtained from the Military University of Technology in Warsaw (MUT) ASG-EUPOS Analysis Centre.

Resultant ZTD estimates and ellipsoidal heights from hourly NRT sessions of 120 days of 2012 were compared to EPN combined estimates. As expected, the average

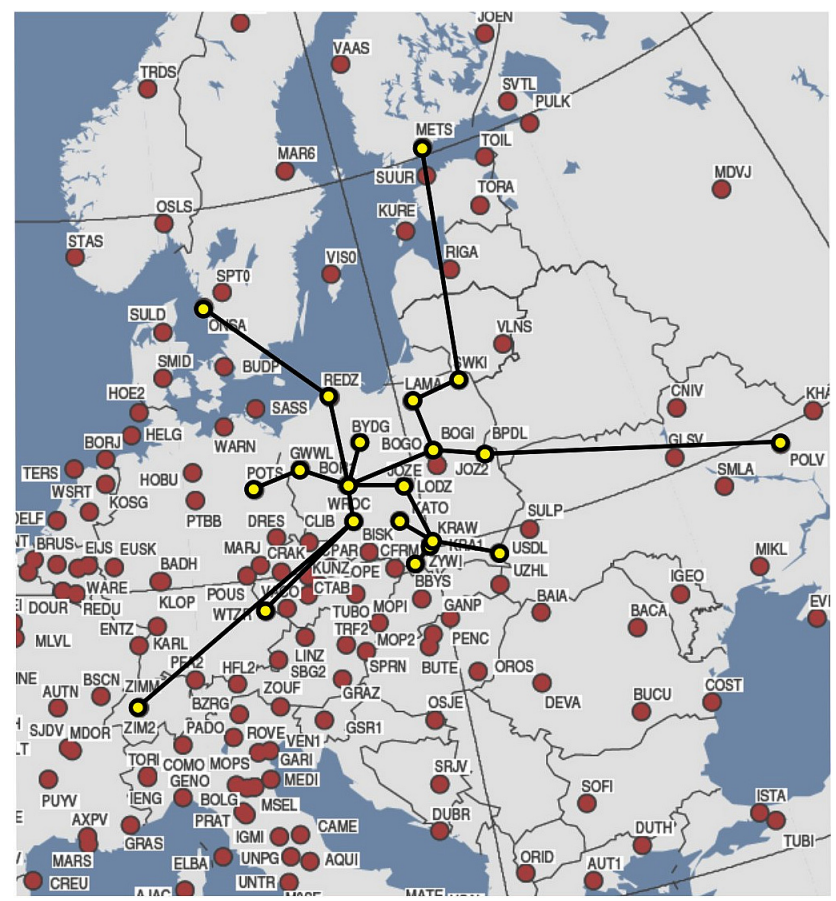

Fig. 7. Baseline skeleton (21 stations) for ASG-EUPOS network solution.

height bias for 30 EPN stations decreased from $-13 \mathrm{~mm}$ to $2.8 \mathrm{~mm}$. Obtained standard deviation of height differences is $25.8 \mathrm{~mm}$. Comparison of NRT ZTD product with EPN combined ZTDs results in average bias of $-0.2 \mathrm{~mm}$ with standard deviation of $13.5 \mathrm{~mm}$. NRT ZTD results from the ASGEUPOS network are also compared to the daily solutions of MUT ASG-EUPOS Analysis Centre, based on IGS Rapid products. The standard deviation of obtained differences over consecutive 120 days of 2012 is $15.5 \mathrm{~mm}$ and the average bias for all processed stations is $0.5 \mathrm{~mm}$.

The sources of presented discrepancies (Fig. 8) may be as follows: the quality of gathered real-time GPS data, used SHORTEST strategy of baselines design, the quality of Ultra-Rapid IGS products, different baseline design and different solution's reference stations. The overall quality of achieved solutions given by standard deviations of ZTDs discrepancy are twice as bad compared to the results coming from GOP (Dousa, 2010b). Achieved results may not be qualified as bad considering the processing of only the last hour of GPS data without combining with previous results and using forced baselines design supported with SHORTEST strategy. This indicates the need for further processing procedure development, especially for the GPS and orbit data quality monitoring. 
Table 3. Summary of basic information on the NRT GPS data processing at Institute of Geodesy and Geoinformatics in Wroclaw.

\begin{tabular}{ll}
\hline \multicolumn{2}{c}{ L5/L3 (code \& phase) strategy } \\
\hline Reference frame & ITRF 2008 (for the epoch of measurements) \\
Number of stations & 103 (97 ASG-EUPOS/Polish EPN \& 6 foreign EPN) \\
Length of processing window & $1 \mathrm{~h}$ \\
A priori ZTD model/mapping function & Saastamoinen/Dry Niell \\
Estimated ZTD model & Wet Niell \\
Ionosphere model & CODE ultra-rapid \\
Baseline design & Forced for core network and based on IGS/EPN stations, \\
& for other stations SHORTEST \\
Ambiguity resolution & wide-lane (L5) \& narrow-lane (L3) \\
Average percentage of resolved ambiguities & $91.4 \%$ (L5) \& 79.4\% (L3) \\
\hline
\end{tabular}

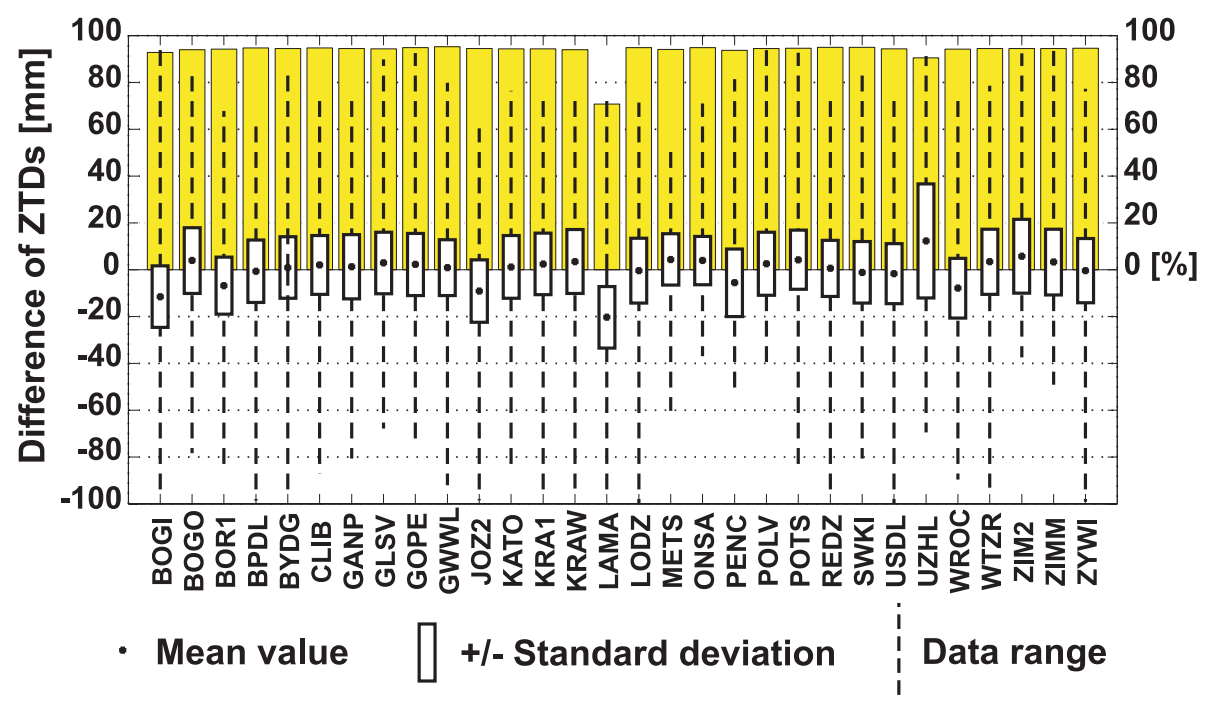

Percentage of ZTD differences within $+/-2$ std. dev.

Fig. 8. Comparison statistics of estimated NRT ZTDs for 30 EPN stations with EPN combined weekly solution for a period of 120 days in 2012.

\section{Water vapour modelling}

The information about contents of water vapour (2-D model) above GNSS stations, represented by Integrated Water Vapour (IWV), is obtained directly from ZWD. The relation between ZWD and the water vapour content in the atmosphere is expressed by IWV and given by the equation (Bevis et al., 1992, 1994; Kleijer, 2004):

$\mathrm{IWV}=\frac{\mathrm{ZWD}}{10^{-6} \cdot R_{\mathrm{W}}}\left(k_{2}^{\prime}+\frac{k_{3}}{T_{\mathrm{M}}}\right)^{-1}$

where $R_{\mathrm{W}}=461.525 \pm 0.003\left[\mathrm{~J} \mathrm{~kg}^{-1} \mathrm{~K}^{-1}\right]$ is the specific gas constant for water vapour, $k_{2}^{\prime}=24 \pm 11\left[\mathrm{~K} \mathrm{hPa}^{-1}\right]$, $k_{3}=3.75 \pm 0.03\left[10^{5} \mathrm{~K}^{2} \mathrm{hPa}^{-1}\right]$ are refraction constants (Boudouris, 1963) and $T_{\mathrm{M}} \approx 70.2 \pm 0.72 \cdot T_{0}$ is weighted mean water vapour temperature of the atmosphere, $T_{0}$ is the surface temperature (Mendes, 1999; Kleijer, 2004).
The ZWD values is derived from equation:

$\mathrm{ZWD}=\mathrm{ZTD}-\mathrm{ZHD}$

where the calculation procedure of ZTD was described in the previous section, and ZHD are derived from Saastamoinen model (1972). The input parameters for ZHD calculations are surface meteorological parameters (temperature, pressure) interpolated for ASG-EUPOS stations as described earlier. Therefore, it is possible to derive IWV for any location inside the GBAS network as presented in Fig. 9. There are no assumptions about the temperature or air-pressure profiles, since only surface values are used. Information about humidity, which is usually derived with insufficient quality and resolution, is unused in this case.

To estimate the 3-D distribution of water vapour in the troposphere, a tomography method was applied. The input data of GNSS tomography are: the signal Slant Wet Delays 

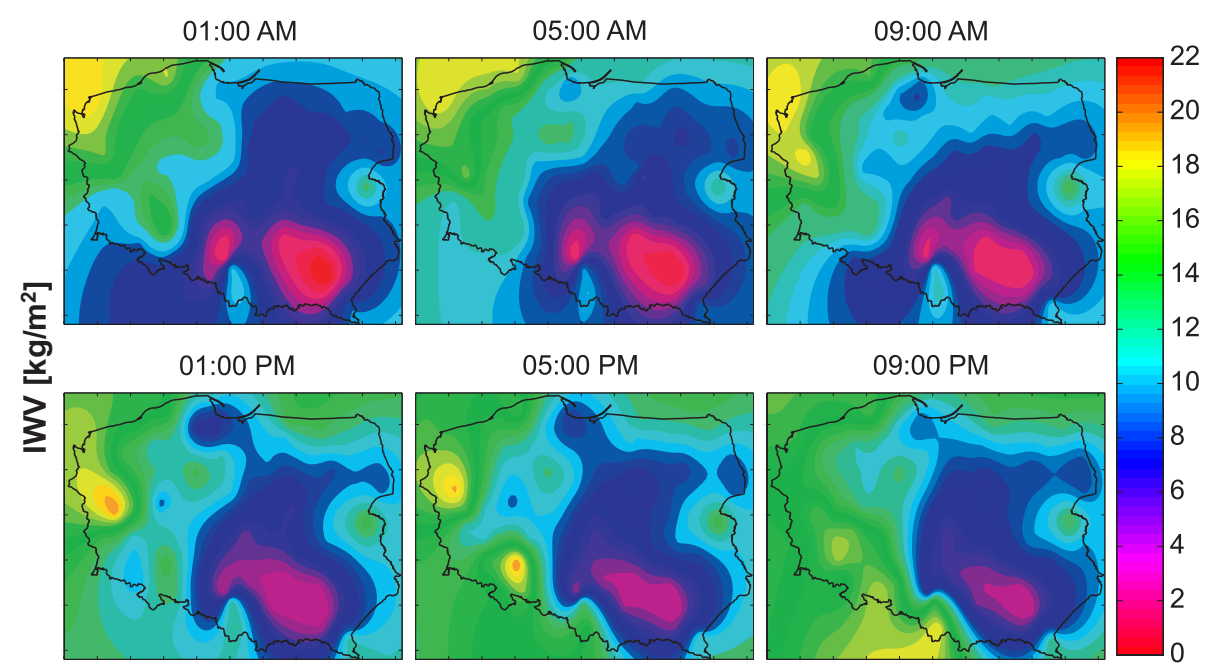

Fig. 9. Example of the Integrated Water Vapour (IWV) 2-D distribution over the area of Poland calculated for 7 November 2011, shown as a time series with $4 \mathrm{~h}$ interval.

(SWD) from GNSS stations, the meteorological observations from synoptic stations and the NWP models data. The NWP models data are also used for GNSS data verification and calibration of the tomography model (Bosy et al., 2010a). The SWD is computed from know equation:

$\mathrm{SWD}=m_{\mathrm{W}}(\varepsilon) \mathrm{ZWD}$

where ZWD is Zenith Wet Delay, $\varepsilon$ is the satellite elevation angle and $m_{\mathrm{w}}(\varepsilon)$ is the mapping function (Niell, 1996; Boehm et al., 2006). In this study, no horizontal variability has been considered, and Double Difference (DD) residuals has not been applied. The GNSS signal delays due to the water vapour are evaluated for a large number of different views through the atmosphere (Bender and Raabe, 2007). The concept of GNSS tomography model for Poland is presented in Fig. 10 (Bosy et al., 2010b).

The tomographic method presented in this paper uses GNSS SWD in conjunction with the minimum constraint conditions imposed on the unknowns (constraints $W$ ) or a priori observations $A_{\text {apriori }}$, or all three components together, what converts the system (2) into:

$$
\left[\begin{array}{c}
\mathrm{SWD} \\
N_{\text {aprioir }} \\
0
\end{array}\right]=\left[\begin{array}{c}
A \\
A_{\text {apriori }} \\
W
\end{array}\right] \cdot N_{w}
$$

The Eq. (11), is solved for unknown $N_{\text {w }}$ with the pseudoinversion procedure applying SVD. Singular Value Decomposition (Anderson et al., 1999). According to previous findings based on theory of error propagation (Rohm, 2012), the precision of unbiased solution for a single epoch should stay well below $2.0 \mathrm{~mm} \mathrm{~km}^{-1}$ in terms of wet refractivity, and assuming standard troposphere temperature gradients, should not be worse than $1 \mathrm{hPa}$ in terms of water vapour partial pressure.

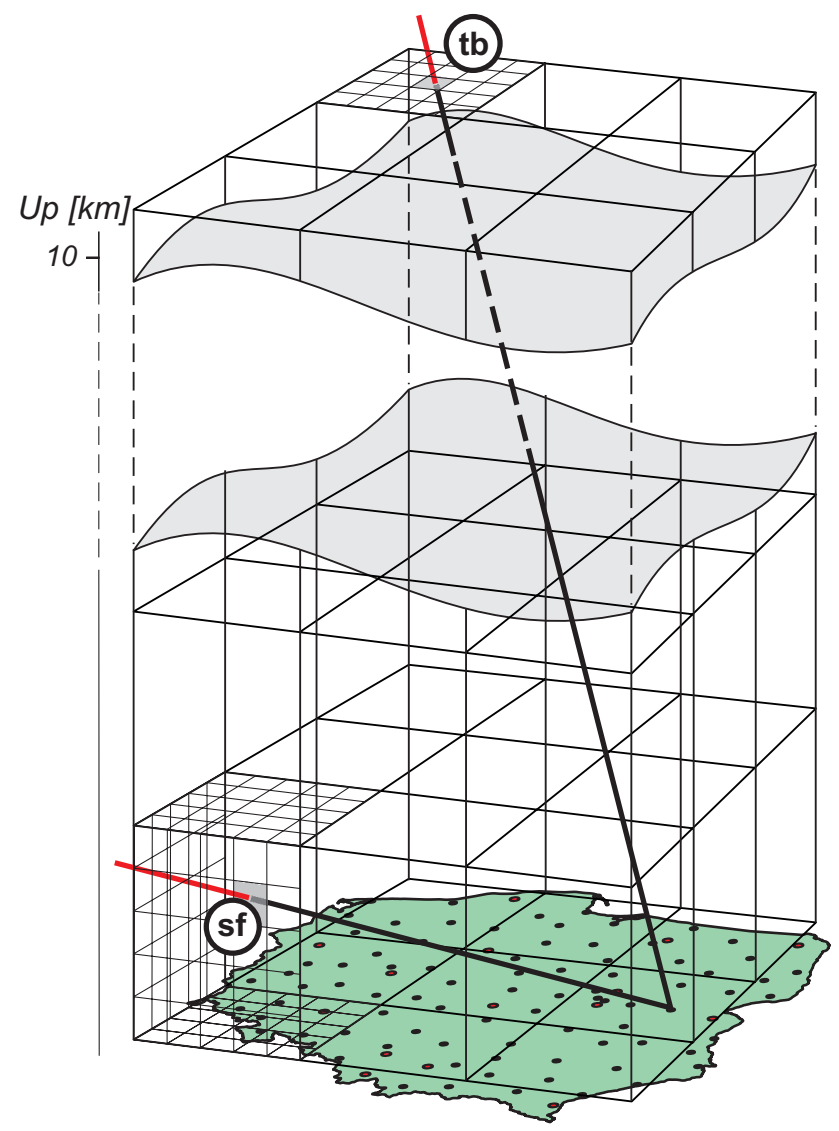

Fig. 10. The ray path in consecutive voxels. Two cases are considered, the first when the ray is coming out of the model's side face (sf), and the second, when ray is coming out of the model top boundary $(\mathrm{tb})$.

The present stage of development of tomography model (TOMO2) is the combined effort of consecutive research stages:

www.ann-geophys.net/30/1379/2012/ 


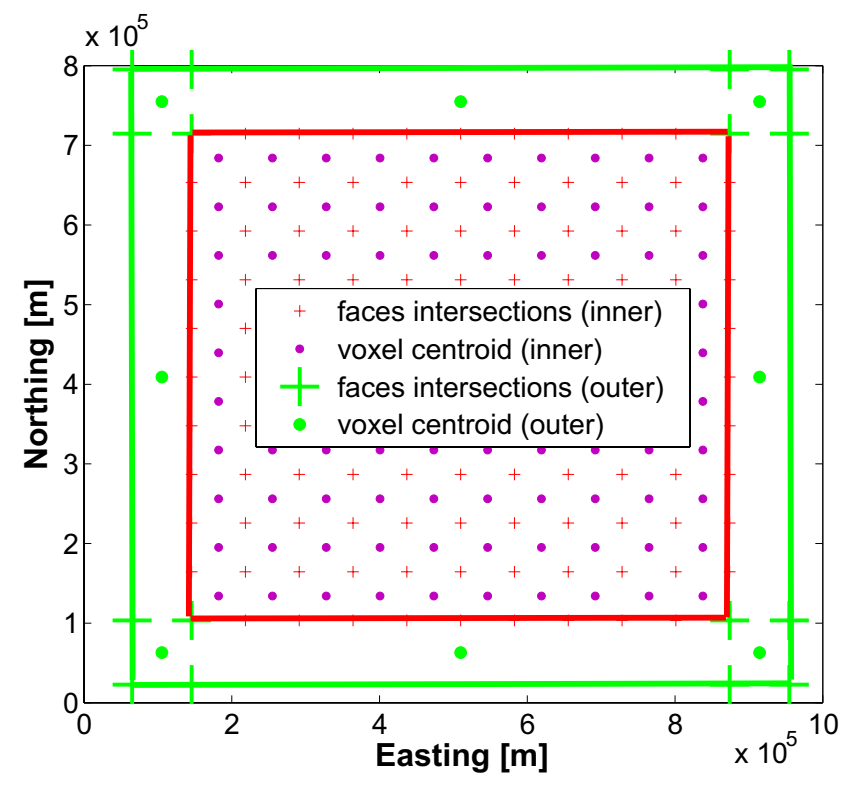

Fig. 11. The setup of tomography nested models, green line represents outline outer model, while red line shows limits of inner model.

- development of algorithm for tomographic inversion based on simulated data (Rohm and Bosy, 2009),

- constructing the method to effectively interpolate meteorological variables ( $p, T, \mathrm{RH})$ (Bosy et al., 2010a),

- validation of the method with external data like Numerical Weather Prediction model (Rohm and Bosy, 2011),

- conceptualisation of NRT processing (Bosy et al., 2010b),

- determination of method precision (Rohm, 2012).

Voxels in the tomography model are organised similarly to the structure of NWP model, and consistent with previous findings (Rohm, 2012), stating that tomography model above $7 \mathrm{~km}$ in height is unable to detect any changes of water vapour content due to precision lower than the usual amount of water vapour in this region of troposphere. Thus, the model in a vertical direction has been separated into $1 \mathrm{~km}$ thick layers, up to $7 \mathrm{~km}$ height.

Another important characteristics related to the model construction is an outer model (Fig. 11), as in forecasting NWP models, covering the state of the atmosphere outside the domain of study, but still having impact on processes observed in the inner model. The reason behind appending the inner model with the outer model is to consider all scanning rays leaving the inner model side faces ( $s f$ in Fig. 10). Although this approach increases the number of unknown parameters in the solution step, but at the same time prevents the solution from large biases introduced by low elevation signals. The outer model is populated with forecasts

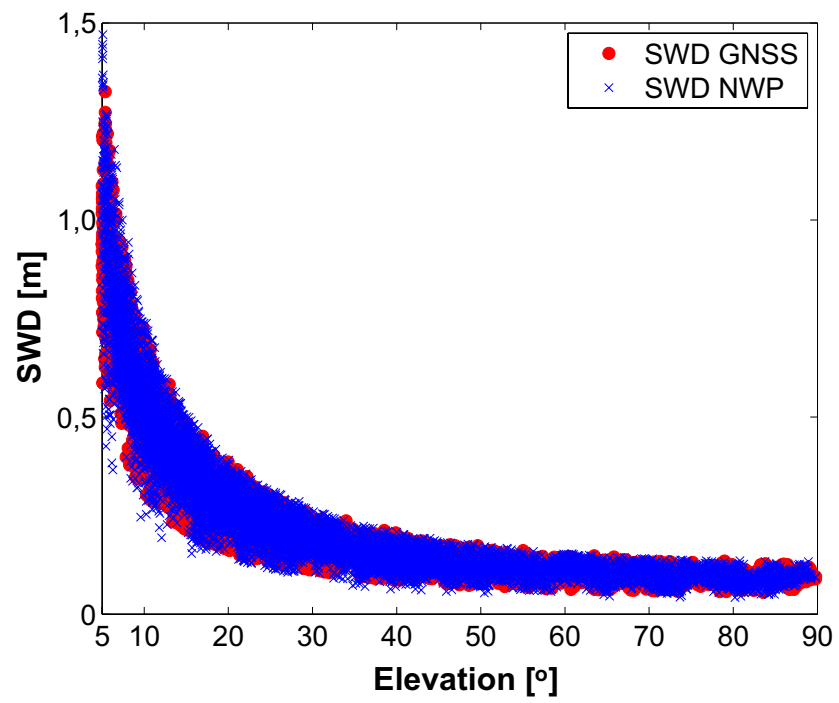

Fig. 12. The SWDs stemming from raytracing through the NWP model (blue), overlayed on SWDs from GNSS processing (red). Each point represents one SWD in relation to the elevation angle, the number of points equals the amount of SWD observations per day in AGS-EUPOS network.

by NWP wet refractivity data and introduced as an a priori values in Eq. (11) the values are estimated in each update step of kalman filter, loose constraints are imposed on this parameter.

To assess the capability in obtaining precise and unbiased estimates of wet refractivity in the troposphere over the territory of Poland, the ZWD for each station in each epoch and SWD for each station satellite couple in each epoch have been validated against raytraced observations from COAMPS (Coupled Ocean/Atmosphere Mesoscale Prediction System) NWP model (Hodur, 1997). The NWP model outputs comprises of pressure, temperature and water vapour pressure in node points of terrain following grid points. Vertically the model has 30 layers while the horizontal resolution for fine grid in nested model equals roughly $22 \mathrm{~km}$. Model delivers full solution every $1 \mathrm{~h}$, consistent with the ZTD estimation process, meteorological parameters were interpolated to the central point of each voxel applying methodology given in Bosy et al. (2010a). The same procedure was applied on the pressure values to derive ZHD and attained ZWD according to Eq. (1), the final solution would be based on ground meteorological observations or forecasts, to keep the model bias free.

As seen in Figs. 12 and 13, the difference between observed and raytraced SWD is rather low with typical statistics, expressed as a standard deviation of $\sigma_{\mathrm{SWD}}=0.049 \mathrm{~m}$ and mean of $\mu_{\mathrm{SWD}}=-0.002 \mathrm{~m}$. The discrepancies are growing larger in low elevation angles (Fig. 12). It is also of interest to see (Fig. 12) that real observations give a somewhat broader spectrum than raytraced, probably resulting from the fact that the NWP model is a smoothed version of 


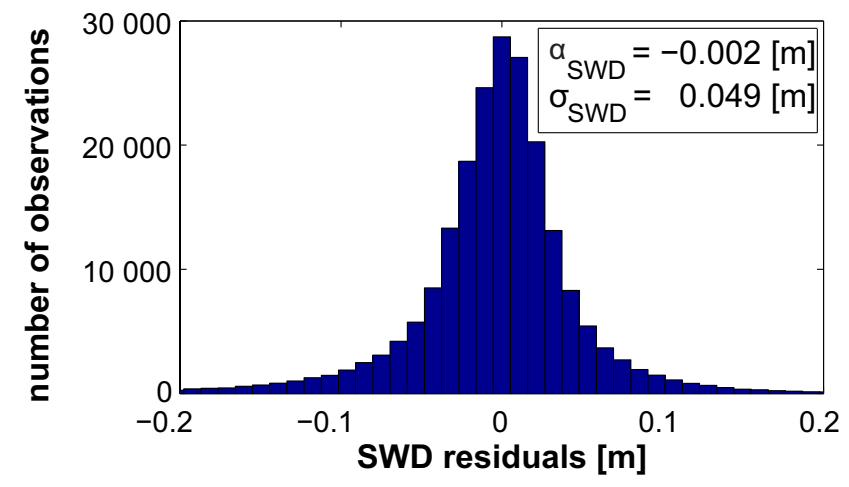

Fig. 13. The residual (SWD GNSS - SWD NWP) histogram showing comparison of the SWD from $24 \mathrm{~h}$ of observations with respective SWD from raytracing through the NWP model, roughly 700000 scanning rays considered.

Table 4. The error settings ( $\mu_{\mathrm{SWD}}-$ bias, $\sigma_{\mathrm{SWD}}-$ standard deviation) for noise analysis (second and third column), with the noise responses from the model ( $\mu_{\mathrm{Nw}}-$ bias, $\sigma_{\mathrm{Nw}}-$ standard deviation) in the fourth and fifth column. Last column shows condition number $k$ of design matrix.

\begin{tabular}{cccccc}
\hline Epochs & $\begin{array}{c}\mu_{\mathrm{SWD}} \\
{[\mathrm{m}]}\end{array}$ & $\begin{array}{c}\sigma_{\mathrm{SWD}} \\
{[\mathrm{m}]}\end{array}$ & $\begin{array}{c}\mu_{\mathrm{Nw}} \\
{\left[\mathrm{mm} \mathrm{km}^{-1}\right]}\end{array}$ & $\begin{array}{c}\sigma_{\mathrm{Nw}} \\
{\left[\mathrm{mm} \mathrm{km}^{-1}\right]}\end{array}$ & $k$ \\
\hline 96 & 0.000 & $1 \times 10^{-6}$ & -0.5 & 4.3 & $5 \times 10^{3}$ \\
96 & -0.002 & $5 \times 10^{-2}$ & -0.2 & 5.2 & $5 \times 10^{3}$ \\
96 & -0.002 & $5 \times 10^{-1}$ & 1.6 & 27.0 & $5 \times 10^{3}$ \\
\hline
\end{tabular}

the troposphere and might not capture all water vapour structures present in the troposphere. To effectively test the impact of noise in the observations, tomographic solution in a controlled environment was performed, results are shown in the Table 4.

The reference value for noise $\sigma_{\mathrm{Nw}}$ and $\mu_{\mathrm{Nw}}$ for given design matrix A (Eq. 11) was established using zero noise assumption in the observations $\sigma_{\mathrm{SWD}}=1 \times 10^{-6} \mathrm{~m}$ and $\mu_{\text {SWD }}=0.000 \mathrm{~m}$. The noise of the solution measured as a standard deviation of discrepancy between reference wet refractivity (NWP) and tomography derived wet refractivity is in the order of $\sigma_{\mathrm{Nw}}=4 \mathrm{~mm} \mathrm{~km}^{-1}$ (first row in Table 4).

From the error propagation analysis, described in Rohm (2012), and Figs. 13, 12, the noise in the GNSS derived SWDs is in the order of $\sigma_{\mathrm{SWD}}=0.005-0.05 \mathrm{~m}$. Hence, random noise of similar magnitude was applied to the observations (SWDs), due to the high condition number $k$ and not reduced with any constraints equations, the output noise was amplified to the unacceptable measure of $\sigma_{\mathrm{Nw}}=$ $27.0 \mathrm{~mm} \mathrm{~km}^{-1}$, almost $30 \%$ of wet refractivity value on the ground level (last row of Table 4).

The intermediate level of noise in the order of $\sigma_{\mathrm{SWD}}=$ 0.001-0.01 $\mathrm{m}$ applied on the same SWD observations with the same observation setup, shows only slightly less precise $\sigma_{\mathrm{Nw}}=5.2 \mathrm{~mm} \mathrm{~km}^{-1}$ (second row of Table 4) results while

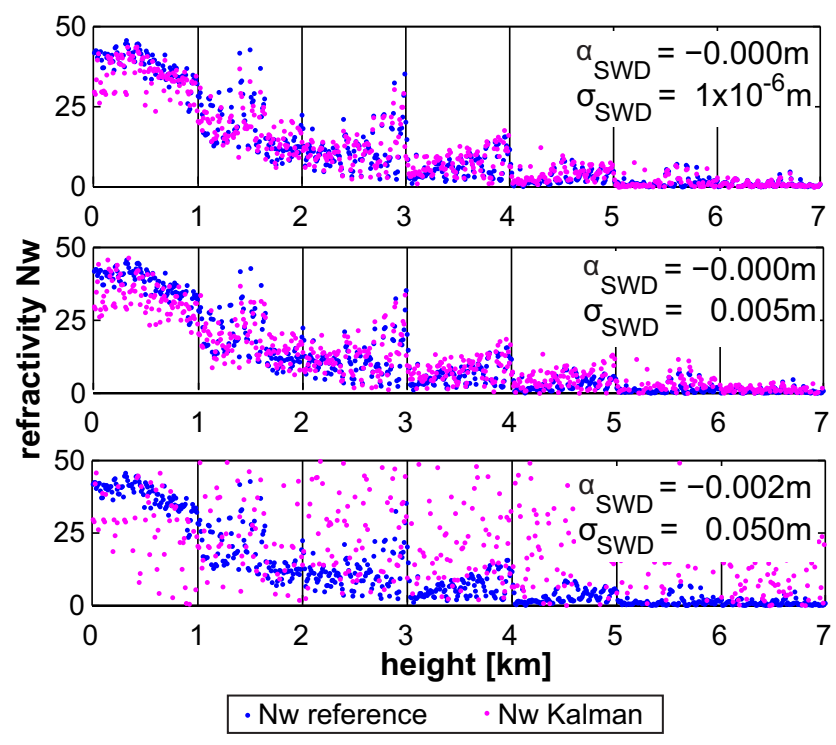

Fig. 14. The selected solution for one epoch, with different magnitude of applied noise, from top to bottom zero, intermediate, realistic.

compared with benchmark observations with no additional noise $\sigma_{\mathrm{Nw}}=4.3 \mathrm{~mm} \mathrm{~km}^{-1}$. Practically, it means that the intermediate level of noise $\left(\sigma_{\mathrm{SWD}}=0.001-0.01 \mathrm{~m}\right)$ is acceptable in the current tomography model setup.

The same patterns as in Table 4 are shown in Fig. 14, where three different observation noise setups were depicted, but only for one selected epoch of observations. The first two top panels look almost the same, they correspond to the first two rows of Table 4 , so with no noise, or with a lowintermediate level of noise. It is clearly seen that both plots are following the same patterns and discrepancies are minor. The bottom panel of the Fig. 14 represents the solution based on simulated observations with realistic random noise, in this case, the solution shows major discrepancies between NWP derived and tomography derived values.

In the final stage of this section, results of processing the real GNSS derived SWDs data are discussed in the context of noise analysis given above. The overall noise of GNSS NRT ZTD data (Fig. 8), and error analysis (Rohm, 2012), shows that the noise of SWD is in the order of $\sigma_{\mathrm{SWD}}=0.005-$ $0.05 \mathrm{~m}$, according to simulation (Fig. 14, bottom panel), wet refractivity from tomography processing should be very noisy. Indeed, the overall solution for 240 epochs 10 days for $24 \mathrm{~h}$ shows discrepancy, measured as a standard deviation between NWP and tomography in the order of $\sigma_{\mathrm{Nw}}=$ $27 \mathrm{~mm} \mathrm{~km}^{-1}$. There are two main reasons for such inaccurate results: first is the quality of the input data, and second is the high condition number $k$. The data quality should be seen as a combination of noise, bias and residual outliers. The noise reduction in this study is limited to increasing cut off angle from 5 degrees to 10 degrees, while other paths would be explored in future (gradients, differential observations). The 


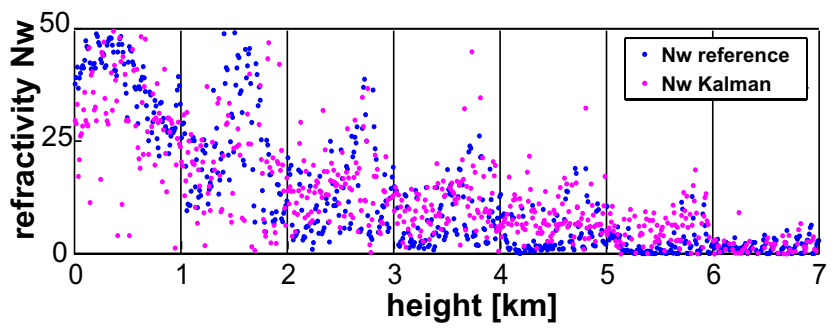

Fig. 15. The example of tomographic solution for one epoch during experiment. Cyan dots represent solution derived with Kalman filter and based on GNSS derived SWDs; blue dots obtained from NWP model.

bias, on the other hand, as shown in this study is more related to discrepancy between NWP data and GPS data (Fig. 15), and according to Table 4 has a small impact on overall solution. Outliers reduction scheme is based on ZTD estimation precision, all observations with larger than a certain threshold value was excluded. The other side of this ill-conditioned tomography problem is the condition score here equals to $5 \times 10^{3}$. This is a result of many factors like: ASG-EUPOS network sites location, GPS system only observations, and 100 voxels in one layer with 7 consecutive layers of $1 \mathrm{~km}$.

The condition number by definition is a difference between first and last singular values in the design matrix. To reduce this score the maximum value for condition number was fixed, due to a rather high noise in data the threshold score was set to 100 . The overall solution improved, the discrepancy between NWP wet refractivities and GNSS tomography wet refractivities measured as a mean standard deviation was reduced to $\sigma_{\mathrm{Nw}}=8.9 \mathrm{~mm} \mathrm{~km}^{-1}$. Future investigations will focus on noise reduction and an increasing number of observations, high frequency observations, new satellite constellations and new satellite based observations.

\section{Conclusions}

In this study, ground-based GBAS network equipped with GNSS and meteorological sensors and external meteorological stations are utilised to derive the estimate water vapour distribution in the troposphere in near real-time.

The NRT ZTD estimation results are comparable with EPN analysis centres postprocessing solution, the results show a consistency between developed strategy for NRT processing and the reference EPN solution. The final average bias for ZTD is on the level of $0.5 \mathrm{~mm}$ for all processed stations with $15 \mathrm{~mm}$ of standard deviation.

Interpolation procedure presented in this paper was applied to extract ZHD from ZTD and finally deliver IWV parameter for all GNSS ASG-EUPOS stations. This standard GNSS meteorology product shows daily distribution of water vapour above operation area of ASG-EUPOS GBAS.
The tomography model on the study area has been setup and initial run has been performed. Simulation of bias and random error imposed on perfect simulated observations reveals the maximum acceptable level of SWD data noise to be $5 \mathrm{~mm}$ in order to achieve $5 \mathrm{~mm} \mathrm{~km}^{-1}$ standard deviation of resulting parameter (wet refractivity).

The ZHD calculation procedure based on ground meteorological observations requires pressure information with accuracy not less than $1 \mathrm{hPa}$, to sustain accuracy of ZTD estimation. This study shows that meteorological station spatial distribution and unhomogenity of sensor results in interpolation procedure not able to deliver expected high accuracy pressure values. Therefore, future investigations should be focused on the meteorological data validation and interpolation with use of NWP models outputs.

The GNSS tomography method gives the possibility to build the 3-D distribution of the water vapour in the neutral atmosphere qualitatively consistent with the NWP models outputs. Therefore, the model of neutral atmosphere created from GNSS and ground meteorological data, could be competitive to NWP models, especially for nowcasting.

Acknowledgements. This work has been supported by the Ministry of Science and Higher Education: research projects No $\mathrm{N}$ N526 197238 and N R09 0010 10, the Head Office of Geodesy and Cartography, the OGIMET service (http://www.ogimet.com) and the Wroclaw Center of Networking and Supercomputing (http: //www.wcss.wroc.pl/): computational grant using Matlab Software License No: 101979.

Topical Editor P. Drobinski thanks two anonymous referees for their help in evaluating this paper.

\section{References}

Anderson, E., Bai, Z., Bischof, C., Blackford, S., Demmel, J., Dongarra, J., Du Croz, J., Greenbaum, A., Hammarling, S., McKenney, A., and Sorensen, D.: LAPACK Users' Guide, Third Edition, Society for Industrial and Applied Mathematics, 1999.

Anthes, R., Ector, D., Hunt, D., Kuo, Y.-H., Rocken, C., Schreiner, W. S., Sokolovskiy, S. V., Syndergaard, S., Wee, T.-K., Zeng, Z., Bernhardt, P., Dymond, K., Chen, Y., Liu, H., Manning, K., Randel, W. J., Trenberth, K. E., Cucurull, L., Healy, S., Ho, S.-P., McCormick, C., Meehan, T., Thompson, D. C., and Yen, N.: The COSMIC/FORMOSAT-3 mission: Early results, B. Am. Meteorol. Soc., 89, 313-333, doi:10.1175/BAMS-89-3-313, 2008.

Bender, M. and Raabe, A.: Preconditions to ground based GPS water vapour tomography, Ann. Geophys., 25, 1727-1734, doi:10.5194/angeo-25-1727-2007, 2007.

Bender, M., Dick, G., Ge, M., Deng, Z., Wickert, J., Kahle, H.-G., Raabe, A., and Tetzlaff, G.: Development of a GNSS water vapour tomography system using algebraic reconstruction techniques, Adv. Space Res., 47, 1704-1720, doi:10.1016/j.asr.2010.05.034, 2011.

Bennitt, G. V. and Jupp, A.: Operational Assimilation of GPS Zenith Total Delay observations into the UK Met Office Numer- 
ical Weather Prediction models, Mon. Weather Rev., 140, 27062719, doi:10.1175/MWR-D-11-00156.1, 2012.

Bevis, M., Businger, S., Herring, T., Rocken, C., Anthes, R., and Ware, R.: GPS meteorology: Remote sensing of atmospheric water vapor using the global positioning system, J. Geophys. Res., (D), 15787-15801, 1992.

Bevis, M., Businger, S., Chiswell, S., Herring, T., Anthes, R., Rocken, C., and Ware, R.: GPS meteorology: Mapping zenith wet delays onto precipitable water, J. Appl. Meteorol., 33, 379386, 1994.

BKG: BKG Ntrip Client (BNC) Version 2.5. Manual, Federal Agency for Cartography and Geodesy, Frankfurt, Germany, 2011.

Boehm, J., Niell, A., Tregoning, P., and Schuh, H.: Global Mapping Function (GMF): A new empirical mapping function based on numerical weather model data, Geophys. Res. Lett., 33, 15-26, doi:10.1029/2005GL025546, 2006.

Borkowski, A., Bosy, J., and Kontny, B.: Meteorological data and determination of heights in local GPS networks-preliminary results, Electronic Journal of Polish Agricultural Universities, Geodesy and Cartography, 5, 2002.

Bosy, J., Figurski, M., and Wielgosz, P.: A strategy for GPS data processing in a precise local network during high solar activity, GPS Solutions, 7, 120-129, 2003.

Bosy, J., Oruba, A., Graszka, W., Leonczyk, M., and Ryczywolski, M.: ASG-EUPOS densification of EUREF Permanent Network on the territory of Poland, Reports on Geodesy, 2, 105-112, 2008.

Bosy, J., Rohm, W., Borkowski, A., Kroszczynski, K., and Figurski, M.: Integration and verification of meteorological observations and NWP model data for the local GNSS tomography, Atmos. Res., 96, 522-530, doi:10.1016/j.atmosres.2009.12.012, 2010a.

Bosy, J., Rohm, W., and Sierny, J.: The concept of the near real time atmosphere model based on the GNSS and the meteorological data from the ASG-EUPOS reference stations, Acta Geodyn. Geomater., 7, 1-9, 2010b.

Boudouris, G.: On the index of refraction of air, the absorption and dispersion of centimeter waves by gases, J. Res. National Bureau of Standards, 67D, 631-684, 1963.

Dach, R., Hugentobler, U., Fridez, P., and Meindl, M.: Bernese GPS Software Version 5.0, Astronomical Institute, University of Bern, 2007.

Dousa, J.: Evaluation of tropospheric parameters estimated in various routine GPS analysis, Physics and Chemistry of the Earth, Parts A/B/C, 29, 167-175, doi:10.1016/j.pce.2004.01.011, 2004.

Dousa, J.: The impact of errors in predicted GPS orbits on zenith troposphere delay estimation, GPS Solutions, 14, 229-239, doi:10.1007/s10291-009-0138-z, 2010a.

Dousa, J.: Precise Near Real-Time GNSS Analyses at Geodetic Observatory Pecný - Precise Orbit Determination and Water Vapour Monitoring, Acta Geodynamica et Geomaterialia, 7, 717, 2010b.

Flores, A., Ruffini, G., and Rius, A.: 4D tropospheric tomography using GPS slant wet delays, Ann. Geophys., 18, 223-234, doi:10.1007/s00585-000-0223-7, 2000.

Grejner-Brzezinska, D. A., Arslan, N., Wielgosz, P., and Hong, C.K.: Network Calibration for Unfavorable Reference-Rover Geometry in Network-Based RTK: Ohio CORS Case Study, J. Surveying Engineering, 135, 90-100, doi:10.1061/(ASCE)0733-
9453(2009)135:3(90), 2009.

Heise, S., Dick, G., Gendt, G., Schmidt, T., and Wickert, J.: Integrated water vapor from IGS ground-based GPS observations: initial results from a global 5-min data set, Ann. Geophys., 27, 2851-2859, doi:10.5194/angeo-27-2851-2009, 2009.

Hirahara, K.: Local GPS tropospheric tomography, Earth Planets Space, 52, 935-939, 2000.

Hodur, R.: The Naval Research Laboratory's Coupled Ocean/Atmospheric Mesoscale Prediction System, Mon. Weather Rev., 125, 1414-1430, 1997.

Järvinen, H., Eresmaa, R., Vedel, H., Salonen, K., Niemelä, S., and de Vries, J.: A variational data assimilation system for groundbased GPS slant delays, Q. J. Roy. Meteorol. Soc., 133, 969-980, doi:10.1002/qj.79, 2007.

Karabatic, A., Weber, R., and Haiden, T.: Near real-time estimation of tropospheric water vapour content from ground based GNSS data and its potential contribution to weather now-casting in Austria, Adv. Space Res., 47, 1691-1703, doi:10.1016/j.asr.2010.10.028, 2011.

Kee, C., Parkinson, B. W., and Axelrad, P.: Wide Area Differential GPS, Navigation, 38, 123-146, 1991.

Kleijer, F.: Troposphere Modeling and Filtering for Precise GPS Leveling, Ph.D. thesis, Department of Mathematical Geodesy and Positioning, Delft University of Technology, Kluyverweg 1, P.O. Box 5058, 2600 GB DELFT, The Netherlands, 260 pp., 2004.

Mendes, V. B.: Modeling the neutral-atmosphere propagation delay in radiometric space techniques, $\mathrm{Ph} . \mathrm{D}$. thesis, Deparment of Geodesy and Geomatics Engineering Technical Reort No. 199, University of New Brunswick, Fredericton, New Brunswick, Canada, 1999.

Mervart, L.: Ambiguity resolution techniques in geodetic and geodynamic applications of the Global Positioning System, Ph.D. thesis, Astronomical Institute, Druckerei Universitat Bern, Berne, Switzerland, geodätisch-geophysikalische Arbeiten in der Schweiz, Band 53, Schweizerische Geodätische Kommision, Institut für Geodäsie und Photogrammetrie, Eidg. Technische Hochschule Zürich, Zürich, 1995.

Niell, A. E.: Global mapping functions for the atmosphere delay at radio wavelenghs, J. Geophys. Res., 101, 3227-3246, 1996.

Nilsson, T. and Gradinarsky, L.: Water Vapor Tomography Using GPS Phase Observations: Simulation Results, IEEE Trans. Geosci. Remote Sens., 44, 2927-2941, 2006.

Perler, D., Geiger, A., and Hurter, F.: 4D GPS water vapor tomography: new parameterized approaches, J. Geodesy, 85, 539-550, doi:10.1007/s00190-011-0454-2, 2011.

Rankine, W. J. M. and Bamber, E. F.: Useful Rules and Tables Relating to Mensuration, Engineering, Structures and Machines, BiblioBazaar, LLC, (reprint from 1876), 2009.

Rohm, W.: The precision of humidity in GNSS tomography, Atmos. Res., 107, 69-75, doi:10.1016/j.atmosres.2011.12.008, 2012.

Rohm, W. and Bosy, J.: Local tomography troposphere model over mountains area, Atmos. Res., 93, 777-783, doi:10.1016/j.atmosres.2009.03.013, 2009.

Rohm, W. and Bosy, J.: The verification of GNSS tropospheric tomography model in a mountainous area, Adv. Space Res., 47, 1721-1730, doi:10.1016/j.asr.2010.04.017, 2011.

van der Marel, H.: COST-716 demonstration project for the near real-time estimation of integrated water vapour from GPS, 
Physics and Chemistry of the Earth, Parts A/B/C, 29, 187-199, doi:10.1016/j.pce.2004.01.001, 2004.

Vedel, H. and Huang, X.-Y.: Impact of Ground Based GPS Data on Numerical Weather Prediction, J. Meteorol. Soc. Japan. Ser. II, 82, 459-472, 2004.

Wickert, J., Michalak, G., Schmidt, T., Beyerle, G., Cheng, C., Healy, S., Heise, S., Huang, C., Jakowski, N., Köhler, W., Mayer, C., Offiler, D., Ozawa, E., Pavelyev, A. G., Rothacher, M., Tapley, B., and Arras, C.: GPS radio occultation: results from CHAMP, GRACE and FORMOSAT-3/COSMIC, Terrestrial Atmospheric and Oceanic Sciences, 20, 35-50, doi:10.3319/TAO.2007.12.26.01(F3C), 2009.
Wielgosz, P., Cellmer, S., Rzepecka, Z., Paziewski, J., and GrejnerBrzezinska, D.: Troposphere modeling for precise GPS rapid static positioning in mountainous areas, Meas. Sci. Technol., 22, doi:10.1088/0957-0233/22/4/045101, 2011. 